\title{
ECLIPSES: DESVELANDO SEUS CONCEITOS E MECANISMOS PARA O AVANÇO DA CIÊNCIA
}

\author{
J. W. DA S. BERNARDINO
Instituto Federal de Educação, Ciência e Tecnologia do Rio Grande do Norte
wendel_acura@hotmail.com* \\ Submetido em 31/01/2017 e aceito em 02/08/2019 \\ DOI: 10.15628/holos.2020.5591
}

\section{RESUMO}

Discorre-se sobre a formação dos conceitos sobre eclipses ao longo dos séculos. Trata-se de uma pesquisa bibliográfica que parte da compreensão de que os conceitos servem para explicar os fenômenos e fatos de forma racional e lógica, problematizando-se o fenômeno em estudo em cada momento histórico e contextual. Objetiva-se fazer um levantamento de estudos que tratam sobre os eclipses para desvelar a formação de seus conceitos ao longo dos séculos até o século XXI. Este artigo estrutura-se em quatro tópicos: no primeiro constrói-se uma abordagem em torno dos primeiros registros humanos explicativos sobre eclipses, como representação social de um fenômeno celeste que enviava mensagem aos homens; no segundo discorre-se acerca da construção de novas formas de compreensão conceitual sobre os eclipses; no terceiro faz-se uma reflexão em torno dos estudos sobre os eclipses que ajudaram no avanço da ciência; por fim, no quarto tópico, dá-se continuidade à abordagem sobre os estudos informando a partir desses o mecanismo de funcionamento dos eclipses. Considera-se que no decorrer da história perpassa uma visão cosmológica da ciência, no que tange a formação dos conceitos sobre eclipses. Isso tem permitido conhecer de forma mais aprofundada sobre esse fenômeno por meio da evolução dos conhecimentos derivada do desenvolvimento de técnicas e instrumentos astronômicos que têm permitido a compreensão do sistema cosmológico.

PALAVRAS-CHAVE: Eclipses, Formação de Conceitos, Registros Astronômicos, Avanço da Ciência.

\section{ECLIPSE: EXPOSING ITS CONCEPTS AND MECHANISMS FOR SCIENCE ADVANCEMENT}

\begin{abstract}
Discusses the formation of concepts about eclipses over the centuries. It is a bibliographical research that starts from the understanding that the concepts serve to explain the phenomena and facts in a rational and logical way, problematizing the phenomenon under study in each historical and contextual moment. We aim to make a review studies that deal with eclipses to unveil a formation of their concepts through the centuries to the twenty-first century. This article is structured in four topics: The first is an approach built around two human registers explaining eclipses, as a social representation of a celestial phenomenon that sent a message to men; The second, is a discuss about the construction of new forms
\end{abstract}

of conceptual understanding of eclipses; The third one is a reflection about the studies on eclipses that do contribute in the advance of the science; Finally, in the fourth topic, we give continuity in the approach about the studies reporting from the mechanism of functioning of eclipses. It is considered that throughout history a cosmological view of science permeates, regarding the formation of concepts about eclipses. This has allowed to know more about this phenomenon through the evolution of knowledge derived from the development of astronomical techniques and instruments that have allowed the understanding of the cosmological system.

KEYWORDS: Eclipses, Formation of Concepts, Astronomical Records, Advancement of Science. 


\section{INTRODUÇÃO}

A temática construída neste artigo desenvolve-se em torno da formação dos conceitos sobre eclipses ao longo dos séculos. Trata-se de uma pesquisa bibliográfica que parte da compreensão de que os conceitos servem para explicar os fenômenos e fatos de forma racional e lógica, problematizando-se o fenômeno em estudo em cada momento histórico e contextual nos quais os estudos astronômicos se desenvolveram e possibilitaram novas reflexões, fazendo avançar o conhecimento científico.

Reconhece-se que a conceptualização acerca desse fenômeno astronômico tem evoluído ao longo do tempo, todavia, justifica-se esse estudo como forma de possibilitar reflexões acerca da temática, tendo em vista que são poucas as produções acadêmicas no País dedicadas a esta, conforme consulta no Catálogo de Teses e Dissertações da Coordenação de Aperfeiçoamento de Pessoal de Ensino Superior (Capes), no qual há apenas 35 trabalhos que retornam com o descritor: eclipses. Destes, nenhum, trata especificamente da problemática histórica construída para o estudo do tema aqui discutido, qual seja, como ocorreu a evolução do conceito de eclipses em meio ao desenvolvimento técnico e tecnológico? Todavia, nos possibilitaram conhecer alguns dos referencias teóricos selecionados para esse trabalho. Sendo assim, a motivação para esse estudo encontra-se também na necessidade de sedimentação de conhecimentos acerca desse fenômeno para subsidiar, com base na literatura consultada, uma pesquisa de campo sobre astronomia a qual trata de ensino de Física, tendo como referente de conteúdo - os eclipses.

O objetivo desse artigo parte de um levantamento de estudos que tratam sobre eclipses para desvelar a formação de seu conceito ao longo dos séculos, até o século XXI, atrelada ao desenvolvimento técnico e tecnológico que possibilitou seu avanço.

Utilizou-se como critério de seleção do referencial teórico, constante deste artigo, autores cujos trabalhos são referenciados em obras reconhecidas na produção acadêmica analisada, bem como em trabalhos que foram publicados em periódicos cuja avaliação é feita por pares. Nesse sentido, utilizamos: Barros-Pereira (2011), Faria (1982), Hoffman (1979), Medeiros e Monteiro (2002), Porto e Porto (2008), Reis (2008), Reis, Garcia e Baldessar (2012), Rodrigues (2006) e Rodrigues (2011).

Este artigo além das reflexões bibliográficas é ilustrado com imagens que retratam o que está sendo discutido como forma de ilustração. Desse modo, encontra-se estruturado em quatro tópicos: no primeiro constrói-se uma abordagem em torno dos primeiros registros humanos explicativos sobre eclipses, como explicação de um fenômeno celeste que enviava mensagem aos homens. No segundo discorre-se acerca da construção de novas formas de compreensão conceitual sobre os eclipses. No terceiro faz-se uma reflexão em torno dos estudos sobre os eclipses dando ênfase aos que ajudaram no avanço da ciência. Por fim, no quarto tópico, dá-se continuidade à abordagem sobre os estudos informando a partir desses, os mecanismos de funcionamento dos eclipses. 


\section{REVISÃO BIBLIOGRÁFICA}

\subsection{ECLIPSES: PRIMEIROS REGISTROS}

O Sol e a Lua estão diretamente relacionados às questões cotidianas como o ciclo dia/noite, ciclo das marés e as estações do ano. Essas influenciam atividades econômicas vitais, como pesca e agricultura. Por isso, esses astros tem despertado o interesse humano ao longo dos séculos como afirma, Reis (2008, p. 1), "o Sol e a Lua são os corpos celestes mais próximos da realidade humana na Terra. Apesar de os povos, desde os primórdios da História, serem curiosos a respeito das estrelas e do Universo como um todo, o Sol e a Lua tem sido os principais atores em nosso magnífico teatro celestial."

Acredita-se que, o interesse do homem pela Astronomia é tão antigo quanto a sua própria origem. Há alguns registros antigos que indicam isso, como a escultura de Órion em pedra, de apenas 3,8 cm de comprimento, descoberta em 1974, em uma caverna perto de Blaubeuren, na Alemanha, e estudada pelo pesquisador Michael Rappenglück (Figura 1). Essa pequena peça de pedra tem uma idade de 32 mil anos e está esculpida em baixo relevo. Ainda, não se sabe desde quando a humanidade tem observado eclipses. Sequências de marcas gravadas em ossos de animais datando de aproximadamente 30 mil anos sugerem as fases da Lua, de um ciclo a outro. (HOFFMAN, 1979).

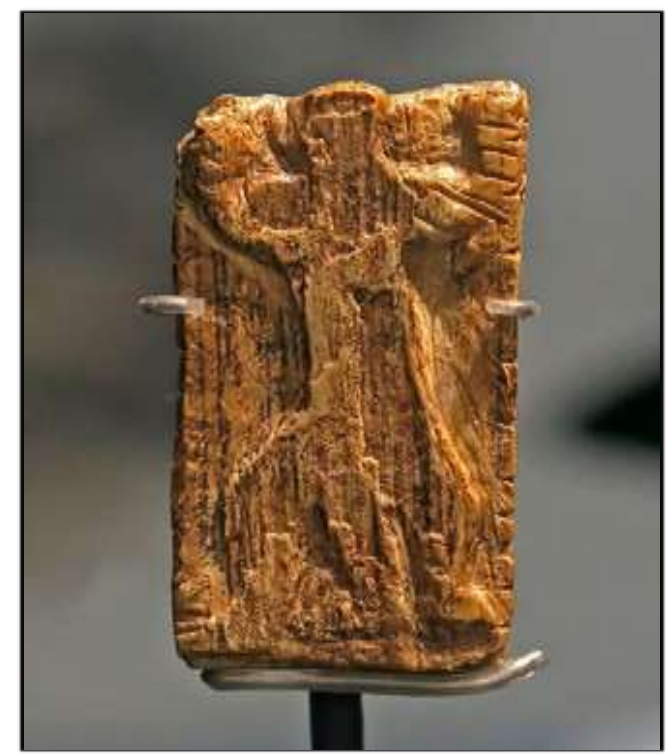

Figura 1: Escultura de Órion em pedra encontrada em uma caverna perto de Blaubeuren, em 1974.

Foto: Don Hitchcock 2015, Original, Württemberg Landesmuseum, Stuttgart

Um fato que não pode ser ignorado é que a partir do momento em que o homem (homo sapiens) passou a reconhecer padrões na natureza para sua sobrevivência -, o céu passou a ser um calendário. Por meio de sua observação passou-se a compreender que sua sobrevivência dependia de ler as estrelas. As mensagens no céu diziam aos nossos antepassados quando acampar e quando se mover; quando os rebanhos selvagens migravam, e quando chegariam o frio e a chuva; e ainda, 
quando cessariam por um tempo. Quando perceberam a direta conexão entre o movimento das estrelas e os ciclos sazonais da vida na Terra concluíram naturalmente que: o que acontecia lá em cima devia afetá-los aqui embaixo. Como afirma Faria (1982, p. 13), "o desconhecimento da verdadeira natureza dos astros deve ter produzido no homem primitivo um sentimento misto de curiosidade, admiração e temor, levando-o a acreditar na natureza divina dos corpos celestes".

Em muitas das sociedades primitivas os costumes eram determinados tendo fundamento nos astros, conforme afirma Faria (1982, p.13):

Aqueles que melhor conheciam os fenômenos celestes foram considerados seus intérpretes, formando elites sacerdotais que dominavam e determinavam os costumes daqueles povos, dando origem a seitas religiosas politeístas e ainda à Astrologia, desenvolvendo a crença na influência dos astros sobre a determinação dos destinos humanos.

Quando a ordem celestial era de alguma forma violada de repente, por algum fenômeno os povos antigos levavam para o lado pessoal. Observa-se que, um tipo de fenômeno em especial mexia com a ordem dos dois principais astros no nosso céu, os eclipses. Quase todos os povos antigos interpretam que: um eclipse deve ser uma mensagem enviada pelos Deuses ou por algum Deus em particular, e quase da mesma forma nossos ancestrais concluíam que as notícias não eram boas.

Os Eclipses são notáveis espetáculos celestes observáveis a olho nu, e ao longo de séculos a humanidade tem se encantado em ver eclipses solares e lunares. Nos tempos antigos os eclipses causavam medo e apreensão, principalmente os eclipses solares, em vista de que as sociedades agrícolas dependiam da luz e do calor do Sol para produzirem sua existência. O temor sobre os eclipses lunares, por sua vez, advinha da sua coloração avermelhada, que, por vezes, remete à cor de sangue, e por isso, eram interpretados como prenúncios de guerra. (REIS, 2012, p. 3).

Algumas civilizações antigas tinham uma forma peculiar de explicar os eclipses:

a) Os chineses acreditavam que os eclipses solares eram causados quando um dragão invisível engolia o Sol (Figura 2), uma antiga tradição chinesa consistia em bater tambores e potes, fazendo barulho para espantar o dragão.

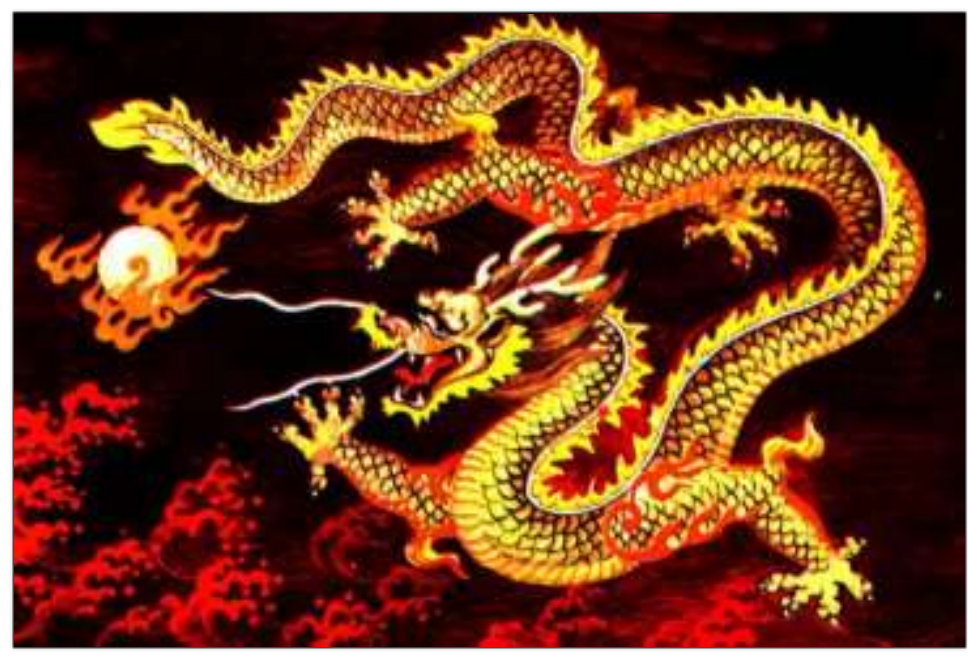

Figura 2: Dragão engolindo Sol - Povos na China antiga e em culturas do Sudeste 
b) Os atenienses, na Grécia antiga, acreditavam que os eclipses (solares ou lunares) eram causados por deuses furiosos; logo, eram considerados mau presságio.

c) Os maias, na América Central, acreditavam que, durante os eclipses lunares, um jaguar gigante devorava a Lua. Ele se movia pela escuridão e sua pele se assemelhava a um céu estrelado.

d) No Japão, poços eram fechados para evitar que a água fosse contaminada pelo suposto veneno que vinha dos céus, proveniente do eclipse.

e) $\mathrm{Na}$ Escandinávia, acreditava-se que dois lobos chamados Skoll e Hat aterrorizavam o Sol e a Lua.

f) Na Índia, um monstro chamado Rahu teria a cabeça de um dragão e a cauda de um cometa. Ele dirigiria uma carruagem puxada por oito cavalos pretos que representavam o céu.

g) Os astecas acreditavam que as Tzitzimine, estrelas-demônio, causavam eclipses quando combatiam o Sol.

h) Na Bolívia, acreditava-se que cachorros corriam atrás do Sol e da Lua e mordiam-nos. Era o suposto sangue da Lua que a deixava avermelhada. A população gritava e gemia para espantar os cães. (REIS, 2012, p. 86).

Pertence aos esquimós à interpretação mais curiosa e original para os eclipses, de acordo com os mesmos os eclipses ocorriam quando os seus dois deuses mais importantes, Padli (o Sol) e Amarok (a Lua) faziam amor (Figura 3).

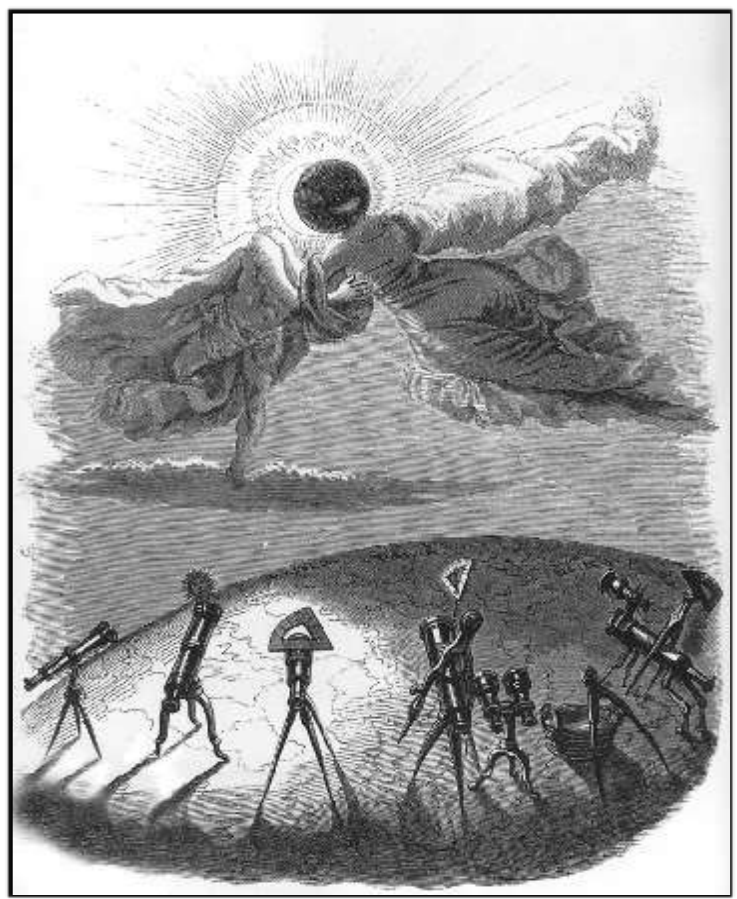

Figura 3: Eclipse Nupcial - Para alguns o Sol e a Lua são amantes que, quando se abraçam, apagam as luzes do céu para assegurar sua intimidade.

Fonte: https://periodicos.ufsc.br/index.php/fisica/article/view/24281 
O que se percebe é que a humanidade ao longo da sua história nunca foi indiferente aos eclipses, sempre citados em escrituras antigas, apontados e explicados envoltos em misticismo, ou como fator determinante de queda e ascensão de impérios, reis coroados ou destronados, vitórias ou derrotas de tropas em batalhas.

\subsection{NOVAS FORMAS DE COMPREENSÃO SOBRE OS ECLIPSES}

Com o passar dos séculos, as sociedades antigas foram acumulando conhecimento sobre os astros por meio de observações realizadas ao longo de várias gerações o que possibilitou um acúmulo de conhecimento. Isso permitiu o desenvolvimento de novas formas de observações e de compreensão para o que sejam os eclipses. Contudo, a mudança da forma de observar os astros já pode ser percebida na idade da pedra, em um momento em que nossos ancestrais construíram sítios megalíticos, formações rochosas devidamente arrumadas na natureza por nossos antepassados. Como afirma Rodrigues (2006, p. 8):

Pode-se afirmar que já na Idade da Pedra o Homem se interessava pela astronomia conforme provam os sítios megalíticos, grandes construções em pedra (cromeleques e alinhamentos), que podem ser observados, por exemplo, em Portugal (Cromeleque dos Almendres), na Escócia (em Callanish), em Inglaterra (círculo de Stonehenge) e na Bretanha (alinhamentos de Carnac). Muitos consideram que estes sítios eram verdadeiros observatórios astronómicos que já na Idade da Pedra permitiriam a previsão de eclipses.

Estudos sobre esses megalíticos indicam que a colocação das pedras em alinhamentos e círculos funcionava como marcador de posições extremas do nascer e do pôr do Sol e da Lua.

Além de monumentos Megalíticos como Stonehenge fornecerem evidências da mudança de forma com que os povos antigos realizavam suas observações, permitindo por meio deles prever o acontecimento de Eclipses, existem registros astronômicos que confirmam essa ideia, Rodrigues (2006, p. 9) corrobora essa ideia ao afirmar que:

Data de 2136 ou 2128 a.C. o registo mais antigo de um eclipse solar e é no clássico chinês TchuKing que ele se encontra. Na Mesopotâmia um registo que data de 1375 a.C. tem a particularidade de ser mais específico porque não se limita a fazer referência a um eclipse solar, precisando que se trata de um eclipse total.

No período babilónio antigo (compreendido entre a queda de Ur e a tomada da Babilónia pelos hiitas), que abrange quase a primeira metade do milénio II a.C., também existem registos de eclipses do Sol 
Esses povos antigos já dispunham de alguns instrumentos astronômicos antigos, como Gnômon e Pólo, que permitiam uma coleta de dados mais precisa e uma observação mais qualitativa do movimento dos astros.

No "Enuma Anu Enlil" uma coleção de documentos mesopotâmicos de interpretação e observações das estrelas, planetas, tempo e ocorrências naturais, no período cassita (que durou aproximadamente cinco séculos estendendo-se até ao final do milénio II a.C.), segundo Rodrigues (2006, p. 9), "existe uma compilação desses textos que contém séries de dados astronómicos incluindo mais de 7000 observações de fenómenos celestes de vários tipos, com particular incidência nos eclipses da Lua".

Pode-se, assim, compreender que o homem na Mesopotâmia dois séculos antes de Cristo, não apenas tentava explicar o que eram, são, os eclipses, mas se preocupava em registrar tais fenômenos para a posteridade.

\subsubsection{Estudos sobre eclipses e o avanço da ciência}

Não há dúvidas que as observações realizadas por pelos chineses e mesopotâmicos tenham um importante valor histórico. Essas observações serviram como base de estudos posteriores. Todavia, foi através de egípcios e gregos que adquiriram conhecimento acerca da mecânica do fenômeno, por meio dos babilônios, que a capacidade de prever eclipses chegou até aos nossos dias.

Mesmo sem o conhecimento que temos hoje sobre os movimentos do Sol, da Terra e da Lua esses povos antigos já conseguiam prever de forma bastante precisa o acontecimento de eclipses solares e lunares, de acordo com Rodrigues (2006, p.54).

Desde a antiguidade que se verificou que ao fim de um determinado intervalo de tempo, denominado Saros (palavra egípcia que significa repetição), a sequência dos eclipses se tornava a repetir. Verificou-se que durante um Saros ocorriam 70 eclipses, 41 dos quais eram solares e 29 lunares.

O ciclo de Saros tem duração aproximada de 18 anos e 11,3 dias. Esse é o período necessário para repetição periódica dos eclipses seguindo uma certa ordem de sucessão. Assim, para que se repita um eclipse do mesmo tipo é necessário que se observem duas condições: "que a lua realize um número inteiro de revoluções em relação ao mesmo nodo da órbita e no término desse período a Lua tem de se encontrar na mesma fase." (RODRIGUES, 2000, p. 112).

Desde a antiguidade os eclipses têm aberto portas a importantes conhecimentos, na Grécia antiga os eclipses lunares foram uma prova da esfericidade da Terra. Esses conhecimentos por permitirem ser observados ao longo da vida foram protagonistas de debates entre Pitágoras, Aristóteles e outros filósofos gregos. Segundo Rodrigues (2006, p. 10) Tales de Mileto (625 a.C. 556 a.C.) foi o primeiro astrónomo grego a prever um eclipse do Sol em 28 de Maio de 585 a.C.. Ao verificarem que a sombra projetada pela Terra na Lua tinha um formato esférico (Figura 4). Compreendeu-se que, a forma daquela sombra representava, portanto, o formato do planeta, 
assim Pitágoras e, posteriormente, Aristóteles (séc. IV a.C.), puderam apontar a esfericidade da Terra.

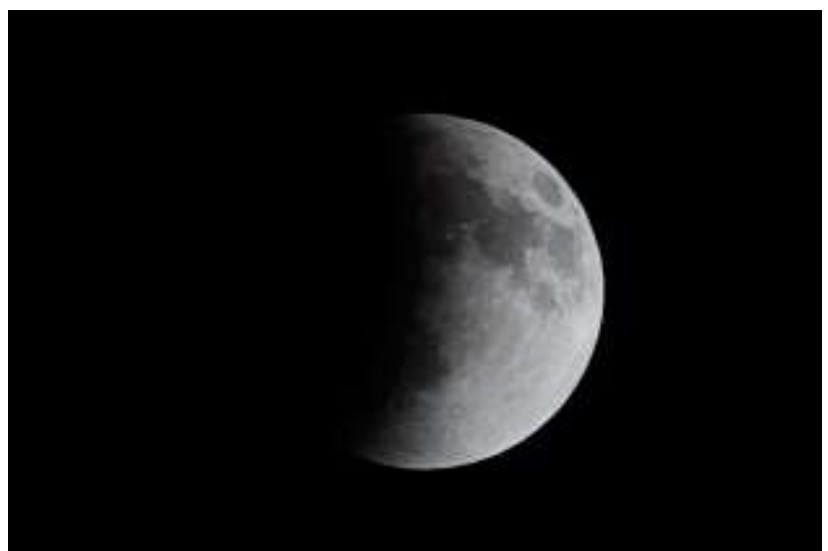

Figura 4: Sombra projetada pela Terra na Lua.

Fonte: http://www.mreclipse.com/LEphoto/TLE2014Apr/TLE2014Apr-1084.html

Mais tarde os estudos feitos por Aristarco (310 a.C. - 220 a.C.) sobre os eclipses permitiram estimar a dimensão dos astros, e também a distância a que estes se encontram da Terra. Reis $(2008$, p. 6) reforça nossas reflexões ao concluir que:

Aristarco (310-230 BCE) utilizou eclipses para estimar os tamanhos relativos da Terra e da Lua pela curvatura do disco lunar e pela curvatura da sombra da Terra nele projetada, estando o Sol, a Terra e a Lua alinhados nessa sequência. Ele também estimou a distância da Terra a Lua e ao Sol, bem como o tamanho do último. Ele demonstrou ainda que o Sol se encontrava mais distante que a Lua e era maior que a Terra.

Outro grego que realizou relevantes estudos baseando-se na formação dos eclipses foi Hiparco (190 a.C. - 120 a.C.), que descobriu a precessão dos equinócios. O mesmo comparou as suas observações (128 a.C.) e as realizadas por Timocárides (295 a.C.), concluiu que os equinócios se deslocavam sobre a eclíptica, em sentido anti-horário, a uma velocidade de 1/71 de grau por ano, dessa forma descobrindo a precessão dos equinócios. Com base nesta descoberta, Hiparco corrigiu o cálculo da duração do ano terrestre e, com esta medida de tempo corrigida, efetuou previsões de eclipses do Sol e da Lua. (RODRIGUES, 2006, p. 11).

O astrónomo grego Ptolomeu formulou por volta de 157 a.C. um complexo esquema de cálculos que permitiam prever a ocorrência de eclipses do Sol e da Lua.

Para esses cálculos Ptolomeu fazia uso do sistema numérico de base sexagesimal. Já era de conhecimento que a órbita lunar possuía uma inclinação aproximada de i $=5^{\circ}$ em relação a "órbita solar". Para prever eclipses lunares Ptolomeu utilizava cálculos que envolviam o diâmetro aparente da Lua, assumindo ser 1/650 da órbita lunar, e o raio da sombra terrestre (umbra) para a distância média da Lua estimado em 2,30 raios da Lua, obtendo as características do referido Eclipse Lunar (Figura 5). (BARROS-PEREIRA, 2011, p. 2602-6). 


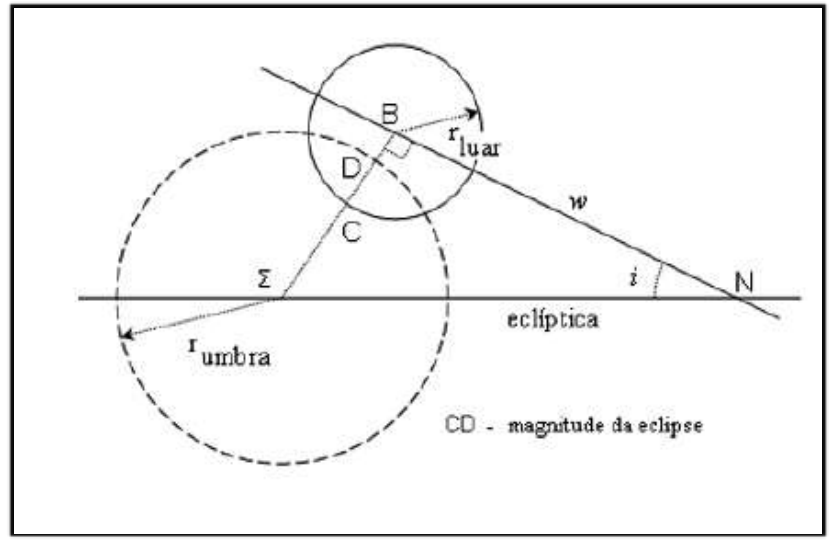

Figura 5: Esquema de Eclipse de acordo com Ptolomeu.

Fonte: http://www.producao.usp.br/handle/BDPI/7046

Diógenes, escritor grego do séc. III, relatou que os astrónomos egípcios dos faraós já haviam registado 373 eclipses do Sol e 832 eclipses da Lua. (RODRIGUES, 2006, p. 12).

Uma fascinante história acerca dos Eclipses aconteceu na era das grandes navegações, quando o célebre navegador Cristóvão Colombo (1451-1506) se viu em uma situação atípica, em 1506, na Jamaica, quando estava na eminência de enfrentar uma rebelião provocada pela falta de mantimentos para a viagem de regresso. Sendo assim, fez uso de uma informação privilegiada de que no dia 10 de Março ocorreria um eclipse solar total, e a usou como meio de pressionar as populações indígenas a cederem às provisões necessárias ao reabastecimento de mantimentos do navio. Ameaçando-os de que os privaria da luz do Sol, caso eles não aceitassem reabastecê-los. A falta de conhecimento sobre os eclipses (ou ingenuidade) levou-os a acreditar na ameaça imediatamente após o astro começar a perder seu brilho. (RODRIGUES, 2006, p. 13).

O eclipse mais importante dos tempos modernos ocorreu em 29 de maio de 1919, de acordo com Reis (2008, p. 7) "quando Arthur Eddington utilizou um eclipse solar para testar a Teoria da Relatividade Geral de Einstein, demonstrando que campos gravitacionais fortes, como o do Sol, são capazes de curvar a luz de estrelas, conforme previsto". Em Rodrigues, (2006, p. 13), encontra-se o complemento dessa informação quando diz:

De acordo com a teoria da relatividade geral de Einstein, de 1915, a luz sofre uma deflexão na presença de um campo gravitacional. Por outras palavras, as trajectórias dos fotões encurvam-se ao passarem por grandes concentrações de massa. Einstein calculou, usando a sua teoria, que um raio de luz emitido por uma estrela e que rasasse a superfície do Sol sofreria uma deflexão de 1",75. Assim, um observador veria essa estrela desviada $1 ", 75$ da sua posição normal. Por outro lado, a teoria da gravitação de Newton, estabelecida no séc. XVII, previa uma deflexão de apenas 0 ",875. Recorde-se que a teoria de Newton, considerando a natureza corpuscular da luz, sustentava que as partículas de luz estariam sujeitas à lei da atraç̧ão universal.

A comprovação da teoria da Relatividade Geral por meio da observação do Eclipse Solar ocorreu quando o conceituado astrofísico britânico, Eddington, propôs realizar, durante o eclipse solar de 1919 (observado no Atlântico Sul, desde o Brasil até a África), observações que permitiam coletar dados do posicionamento das estrelas visualmente próximas do Sol. Essas observações 
foram realizadas por meio de fotografias para que os resultados fossem comparados com os resultados esperados na teoria da Relatividade Geral de Einstein. Para Rodrigues (2006, p. 16):

Eddington organizou duas expedições, uma a Sobral, no Brasil, e outra à Ilha do Príncipe, em África, para proceder às necessárias observações. A primeira teve mais sucesso, pois condições meteorológicas favoráveis tornaram possível realizar sete fotografias das estrelas. Na expedição à Ilha do Príncipe, o céu nublado não permitiu obter mais do que duas fotografias com imagens das estrelas.

O método utilizado por Eddington consistiu na captação de sucessivas imagens no decorrer do Eclipse. A captação foi feita por meio de câmeras acopladas a telescópios. Desse modo, elas captariam de forma mais precisa imagens das posições das estrelas próximas ao Sol. Posteriormente, foi feita a comparação dessas fotografias com outras que haviam sido realizadas seis meses antes, durante a noite. Por meio dessa comparação Eddington pôde constatar e informar a Royal Astronomical Society que os dados obtidos estavam de acordo com a confirmação da teoria de Einstein. (RODRIGUES, 2006, p. 17).

É preciso informar que, isso foi possível porque por volta do final do século XIX, os astrônomos perceberam que a corona solar era essencial para a compreensão de diversos fenômenos solares, como também fenômenos na atmosfera terrestre. Reis $(2012$, p.6) nos explica que: "Os eclipses bloqueiam a fotosfera e revelam a presença de uma atmosfera acima do Sol e além de um raio solar. Esse meio se tornou assunto de extensivo estudo no século dezenove e a observação de eclipses revelou uma porção interior brilhante, a cromosfera, e um halo muito extenso, a corona."

No momento atual, qual seja - no início do século XXI, os eclipses solares são observados pelos cientistas para estudar a superfície solar através de fotografias, e dados espectrográficos da corona solar (Figura 6), somente visível quando o disco brilhante do Sol ou fotosfera é completamente encoberta. A corona solar é constituída por gases ionizados a altas temperaturas. Nela ocorrem explosões térmicas e magnéticas que expelem matéria solar a milhares de quilômetros, pelo espaço. Os eclipses totais do Sol são o momento ideal para estudar o tamanho e a composição da corona solar, além de servir para se estimar as suas diferentes temperaturas e diferentes densidades. (RODRIGUES, 2006, p. 19). 


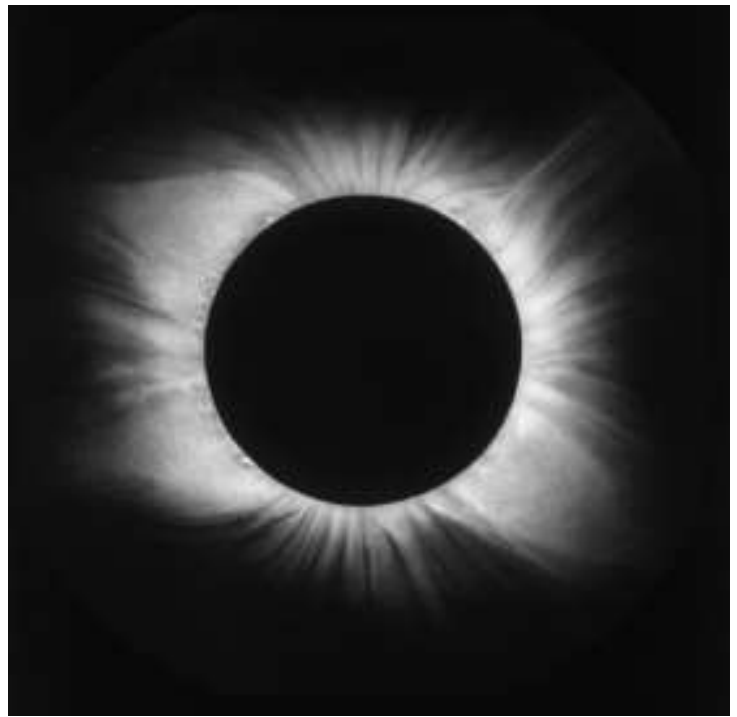

Figura 6: Fotografia de um desenho original, que mostra a corona ao redor do Sol durante um eclipse solar em 22 de Janeiro de 1898, visto em Sahdol na Índia.

Fonte: www.sciencemuseum.org.uk/

Entende-se por essas reflexões que os eclipses tem ao longo dos séculos permitido aos estudiosos e cientistas fazerem observações, que por sua vez contribuíram no passado para comprovar desde a forma geométrica da Terra à Teoria da Relatividade Geral. Atualmente, início do século XXI, as observações desses fenômenos contribuem para o avanço da ciência em relação à explicação da composição e dinâmica da Corona Solar (somente visível quando o disco brilhante do Sol ou fotosfera é completamente encoberta). Cientistas também se aproveitam da ocorrência dos Eclipses para estudar fenômenos relacionados ao clima espacial como as "flares" solares (gigantescas explosões) e a ejeção de matéria coronal, responsáveis por afetar sistemas espaciais e atividades como: telecomunicações, navegação, e o trabalho dos astronautas no espaço.

Atualmente, já no século XXI, o conceito de eclipse bastante aceito é apresentado por Reis (2012) dá conta de que os eclipses são fenômenos naturais provocados pela interposição entre corpos celestes. Isso ocorre quando pelo menos três corpos celestes estão alinhados e um corpo celeste passa pela sombra projetada por outro corpo celeste (como durante um eclipse lunar). Eclipse são fenômenos que mexem diretamente com a aparência momentânea dos principais astros celestes. Na nossa perspectiva, seu acontecimento é geralmente referido em importantes livros e fatos históricos ao longo da história da humanidade.

\subsubsection{Mecanismos de funcionamento dos eclipses}

Eclipses solares e lunares são fenômenos celestes que chamaram desde cedo à atenção das pessoas, por serem notáveis espetáculos celestes. Esses como já apresentados vêm sendo objeto de estudos regulares ao longo das eras. A explicação para os movimentos dos astros do nosso sistema solar evoluiu, como se sabe, do modelo geocêntrico para o modelo heliocêntrico. Esta evolução surgiu da necessidade do homem de explicar os movimentos realizados pelos corpos celestes.

O modelo geocêntrico colocava a Terra no centro do universo com todos os astros realizando revoluções ao seu redor. O primeiro a propor esse modelo foi Aristóteles (séc. IV a.C.). Era à época uma tentativa de explicar os movimentos dos planetas e dos outros corpos celestes, 
de acordo com esse modelo de universo era esférico, finito, eterno e imutável. O Sol, a Lua e os planetas giravam em torno de uma Terra estática, descrevendo circunferências centradas na Terra, com velocidade constante. E cada planeta, assim como também o Sol e Lua estavam presos a uma esfera cristalina, transparente e suficientemente resistente para conseguir suportar o planeta. Presas à esfera exterior encontravam-se as estrelas (Figura 7). (RODRIGUES, 2006, p. 20).

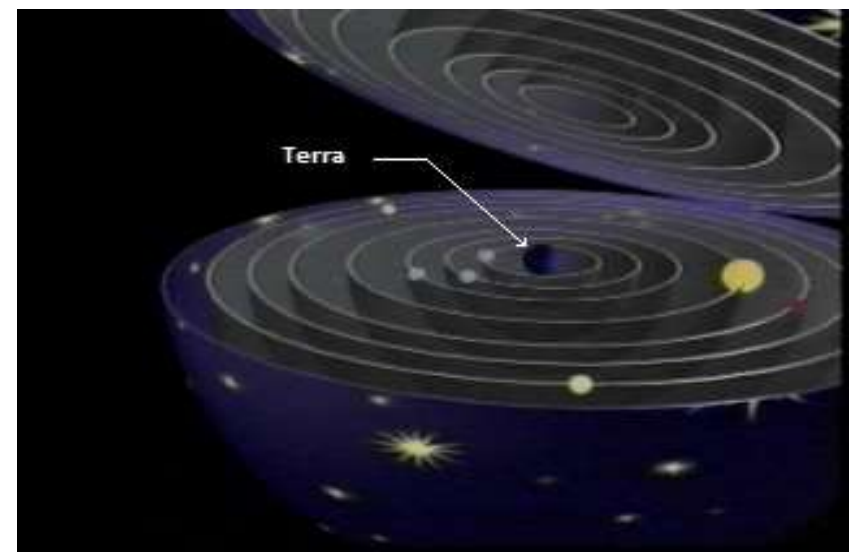

Figura 7: Modelo geocêntrico de Aristóteles - 0 Sol, a Lua, os planetas e as estrelas giram em torno da Terra no centro do universo, presos a esferas cristalinas.

Fonte: http://astro.if.ufrgs.br/p1/geocent.jpg

Essa explicação foi bem aceita até que se observou que o brilho dos planetas variava com o decorrer de tempo. Ptolomeu, em 150 d.C., explicou que esta variação no brilho dos planetas podia ser explicada se as distâncias dos planetas à Terra não fossem fixas, numa tentativa de adequar o modelo Aristotélico às observações, Ptolomeu propôs quatro suposições, segundo Rodrigues (2006, p. 21):

As concepções de Ptolomeu relativamente à estrutura do Universo assentavam em quatro suposições: i) a Terra encontra-se no centro do Universo; ii) a Terra está imóvel; iii) todos os corpos celestes se movem em torno da Terra; iv) os corpos celestes movimentam-se com velocidade constante ao longo de pequenas circunferências (epiciclos), cujos centros se movem em circunferências maiores (deferentes), centradas na Terra. Repare-se que apesar do modelo ter mudado, continuava-se a assumir que as órbitas eram circulares.

O sistema solar sugerido por Ptolomeu se apresentava de forma mais complexa que o proposto por Aristóteles, mas resolvia os problemas das irregularidades observadas no movimento dos planetas (Figura 8). 


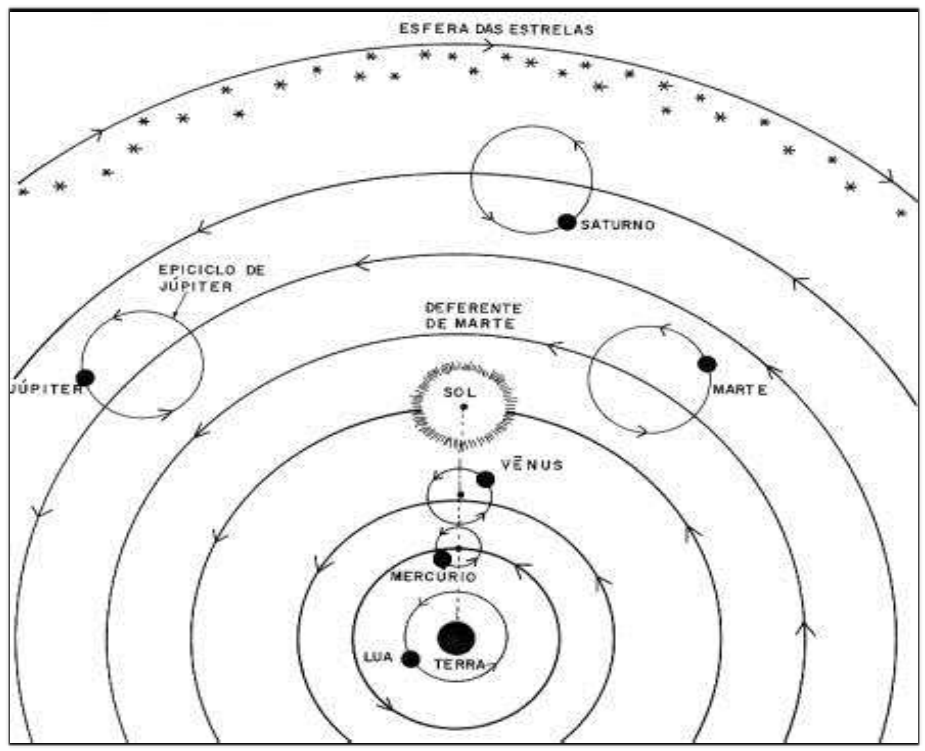

Figura 8: Modelo geocêntrico de Ptolomeu - os planetas movem-se em pequenas circunferências (epiciclos), cujos centros se movem, por sua vez, em circunferências maiores (deferentes), centradas na Terra.

Fonte: http://www.oba.org.br/cursos/astronomia/fundamentoshistastro.htm

Assim, como os movimentos do Sol e da Lua pareciam regulares, mesmo se observados por longos períodos de tempo, no sistema ptolomaico estes astros descreviam uma trajetória circular ao longo de sua deferente, porém sem epiciclos.

O sistema ptolomaico teve bastante êxito na época, pois explicava de forma satisfatória o que era observado. Segundo Rodrigues (2006, p. 22), "O problema surgiu quando a precisão das observações aumentou e se verificou que certas irregularidades observadas nos movimentos aparentes dos planetas não encontravam explicação no modelo ptolomaico".

Tempos depois, foram sendo introduzidos cada vez mais epiciclos ao movimento dos planetas, até que no início do século XVI o sistema ptolomaico tinha se tornado extremamente complicado, e mesmo assim, não explicava algumas observações, como por exemplo, a variação do tamanho aparente da Lua. (RODRIGUES, 2006, p. 21).

No fim da primeira década do século XVI, Nicolau Copérnico apresenta em seu Commentariolus (Pequeno Comentário sobre as Hipóteses acerca dos Movimentos Celestes), o seu sistema astronômico e suas insatisfações com o sistema ptolomaico (MEDEIROS, 2002, p. 31). Rodrigues (2006, p.23) esclarece a questão afirmando que:

Copérnico não aceitava o sistema ptolomaico porque além de o considerar extremamente deselegante, não tinha definido o centro do Universo, uma vez que cada planeta tinha um ponto equante diferente. Mas Copérnico não rejeitou todos os elementos do modelo ptolomaico. Manteve, por exemplo, a ideia de que as órbitas dos planetas eram circulares. Copérnico desenvolveu um modelo em que tudo se movia ao redor de um único centro, o centro do Universo, colocando aí o Sol. 
Segundo o modelo proposto por Copérnico, o Sol ocuparia o centro do universo com a Terra e os demais planetas girariam ao seu redor (Figura 9). De acordo com Porto (2008, p. 4) "Copérnico, no entanto, manteve, ainda sob influência do antigo modelo cosmológico, a ideia de um Universo finito, fechado por esferas, onde os planetas descreviam órbitas circulares perfeitas".

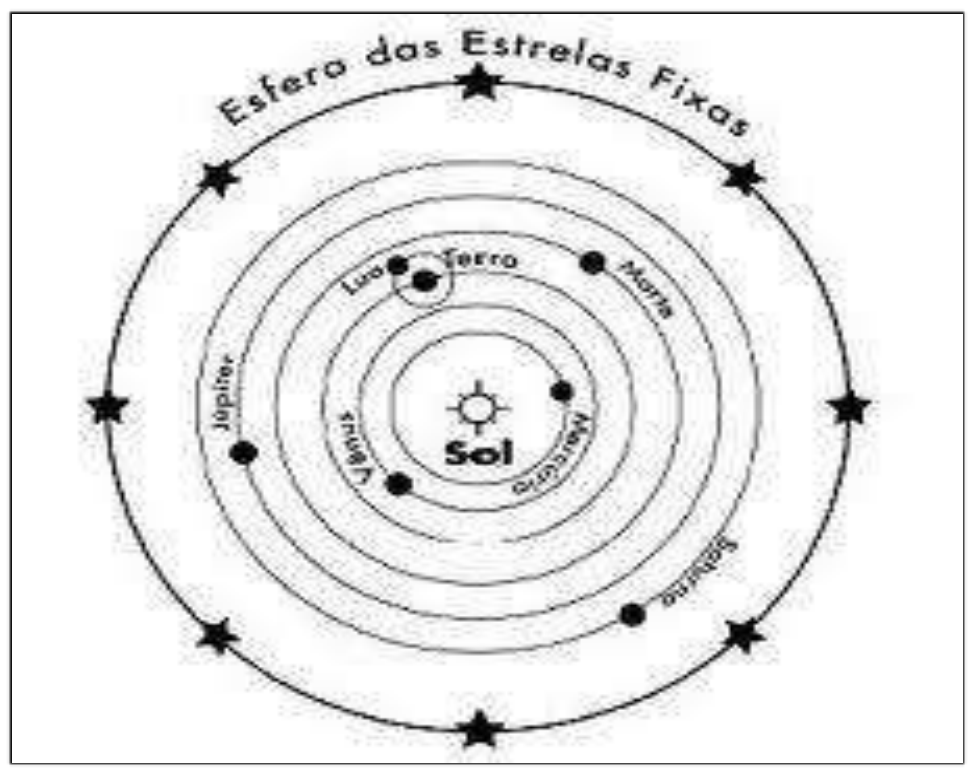

Figura 9: Modelo heliocêntrico de Copérnico - O Sol ocupa o centro do universo com a Terra e os demais planetas girando ao seu redor.

Fonte: http://www.ebah.com.br/content/ABAAAfQnkAK/copernicokepler-galileu

A ideia de um universo infinito só surgiu mais tarde com Giordano Bruno, um fervoroso adepto da teoria heliocêntrica. Inspirado no atomismo grego de Demócrito e Leucipo, ele declarava a realidade de um universo que era infinito, homogêneo, consequentemente sem centro, limites ou quaisquer posições diferenciadas ou privilegiadas, conforme Porto, (2008).

Embora, a teoria de Copérnico simplificasse e descrevesse de forma fiel o movimento dos astros observados da Terra. Ela não foi unanimemente aceita pela comunidade científica, e principalmente pela Igreja Católica, que manteve o livro intitulado De Revolutionibus orbium celestium entre 1616 e 1835 no Índex dos livros banidos, livro publicado em 1543, ano da morte de Copérnico. (RODRIGUES, 2006).

Tycho Brahe (1546-1601) não aceitava inteiramente as ideias propostas por Copérnico, e criou um modelo que se mantinha entre o modelo ptolomaico e o modelo copernicano, pois o mesmo não aceitava que a Terra se movesse. No modelo proposto por Tycho, a Lua, as estrelas e o Sol giravam em torno da Terra, e os demais planetas por sua vez giravam em torno do Sol. Rodrigues (2006, p.24) ressalta que: "Tycho foi o primeiro astrónomo a imaginar os planetas suspensos, sem apoio, no espaço vazio, abdicando assim da ideia das esferas de cristal. Ao longo de 20 anos, Tycho realizou observações precisas de planetas e de estrelas visíveis a olho nu, sem auxílio do telescópio que ainda não tinha sido inventado." 
Kepler (1571 - 1630) ao analisar dados recolhidos por Tycho Brahe sobre a órbita do planeta Marte, constatou em 1605 que a órbita descrita pelo planeta se tratava de uma elipse e não de uma circunferência como acreditavam Copérnico e Tycho. (PORTO, 2008).

As contribuições de Kepler vão muito além desta descoberta, o mesmo formulou três leis que permitem descrever o movimento dos planetas em torno do Sol, das luas em torno dos planetas ou de qualquer outro corpo em órbita no Sistema Solar.

A primeira, Lei das órbitas - diz que os planetas se movimentam ao redor do Sol descrevendo órbitas elípticas (Figura 10), o mesmo ocorre com o movimento das luas em torno dos planetas, e até mesmo com o movimento dos cometas ao redor do Sol. No caso dos planetas, ele descreve sua órbita em torno do Sol, ocupando este um dos focos da elipse.

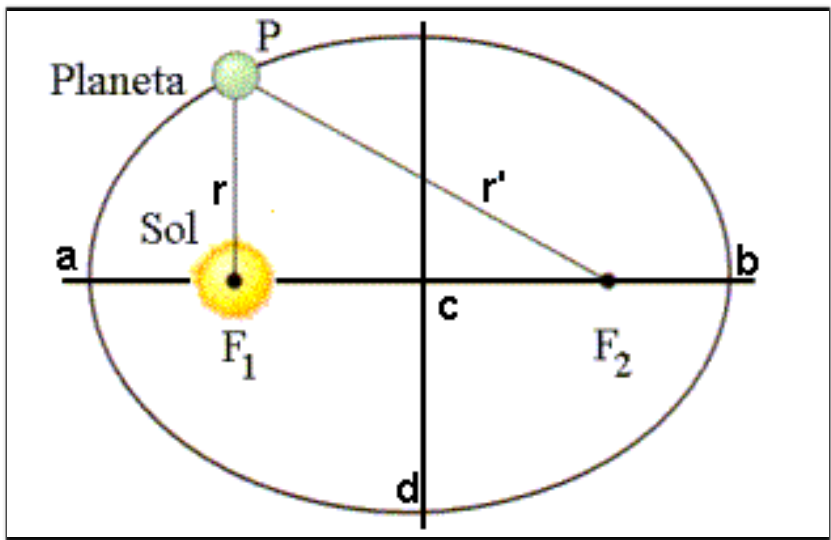

Figura 10 - De acordo com a primeira lei de Kepler, os planetas descrevem órbitas elípticas em torno do Sol, o qual ocupa um dos focos (F1 ou F2).

Fonte: http://www.if.ufrgs.br/tex/fis01043/20041/Diomar/kepler.html

A segunda lei, Lei das áreas - enuncia que à medida que o planeta descreve a sua órbita, o seu vetor posição em relação ao Sol varre áreas iguais em intervalos de tempos iguais (Figura 11).

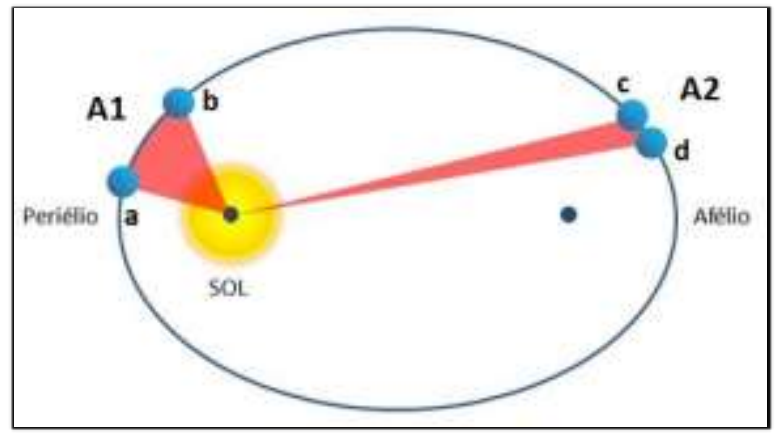

Figura 11 - De acordo com a segunda lei de Kepler, se se as áreas A1 e A2 forem iguais, o tempo que o planeta leva a ir de "a" a "b" é igual ao que leva a ir de "c" a "d".

A terci Fonte: http://portaldoprofessor.mec.gov.br/fichaTecnicaAula.html?aula=26818

de um planeta $\mathrm{T}$, ou seja, intervalo de tempo necessário para que o planeta dê uma volta completa em torno do Sol é proporcional ao cubo do seu semieixo principal maior $\mathrm{R}$, teremos, portanto:

$$
\mathrm{T}^{2} / \mathrm{R}^{3}=\mathrm{k}
$$


Onde $k$ é uma constante que depende apenas da massa do corpo central em torno do qual o planeta gira.

O resultado disso é que: quanto mais afastado do Sol o planeta estiver - maior será o período que este levará para completar uma volta em torno do Sol.

A formulação das leis de Kepler abriu caminho para que mais tarde Isaac Newton (1643 1723) formulasse leis que mostravam a natureza descrita por fórmulas matemáticas e que descrevem o movimento dos corpos. Mas, só a partir desse momento é que se pôde ter a ideia que se sustenta até hoje acerca da formação mecânica dos eclipses. Isso porque nesse momento já se entendia todo o processo de formação dos eclipses e se tinha o domínio de uma estrutura lógicodedutiva por meio dos trabalhos de Kepler e Newton. Esses trabalhos são capazes de prever com bases científicas e com exatidão a formação dos eclipses.

\section{CONSIDERAÇÕES FINAIS}

Considera-se, ao final dessa pesquisa que os objetivos pretendidos foram alcançados de forma satisfatória, pois ao se fazer um levantamento bibliográfico acerca do desenvolvimento do conceito de eclipse, foi possível reconhecer este como um processo cuja construção ocorreu ao longo da história da humanidade, impregnada de contribuições culturais, econômicas e sociais.

De certa forma, nesse estudo foi possível conceber uma visão cosmológica da ciência, possibilitada pelos estudos astronômicos que têm permitido conhecer mais um pouco sobre esse fenômeno e a evolução do seu conceito de forma articulada com o desenvolvimento de técnicas e de instrumentos tecnológicos.

Observou-se, ainda, que no percurso histórico o avanço do conceito de eclipse ocorreu por meio de insatisfação explicativa sobre esse fenômeno o que demandava novas explicações. Assim sendo, confirma-se que os estudos astronômicos acerca de eclipses já realizados vêm contribuindo para a compreensão do sistema cosmológico e impulsionado novos estudos nessa área.

Por fim, desvelar a formação e a evolução de conceitos sobre eclipses e os mecanismos que impulsionaram esse avanço como um avanço da ciência, denota a compreensão de que os trabalhos científicos de Kepler e Newton trouxeram as bases científicas para uma explicação mais exata da formação mecânica dos eclipses.

\section{REFERÊNCIAS}

Barros-Pereira, H. A. D. (2011). Esferas de Aristóteles, círculos de Ptolomeu e instrumentalismo de Duhem. Revista Brasileira de Ensino de Física, 33(2), 2602.

Faria, R. P. (1987). Fundamentos de astronomia. Papirus Editora.

Hoffman, M. A. (1979). Egypt before the pharoahs: the prehistoric foundations of Egyptian civilization. Alfred A. Knopf. 
Medeiros, A., \& Monteiro, M. A. (2002). A invisibilidade dos pressupostos e das limitações da teoria Copernica nos livros didáticos de Física. Caderno Brasileiro de Ensino de Física, 19(1), 29-52.

Porto, C. M., \& Porto, M. B. D. S. M. (2008). A evolução do pensamento cosmológico e o nascimento da ciência moderna. Revista Brasileira de Ensino de Física, 30(4), 4601.

Reis, N. T. O. (2008). Eclipses ao longo dos Séculos. Ministério da Educação - MEC.

Reis, N. T. O., Garcia, N. M. D., \& Baldessar, P. S. (2012). Métodos de projeção para observação segura de eclipses solares. Caderno Brasileiro de Ensino de Física, 29(1), 81-113.

Rodrigues, O. M. A. do C. (2011). O Ciclo solar (Dissertação de Mestrado). Faculdade de Ciências da Universidade do Porto, Departamento de Matemática Aplicada. Porto.

Rodrigues, B. C. G. D. C. (2006). O ensino da Astrofísica no 3o Ciclo do Ensino Básico (Dissertação de Mestrado). Departamento de Física. Universidade do Algarve. Faro. 